\title{
Postdigital as (Re)Turn to the Political
}

\section{Jeremy Knox ${ }^{1}$}

Published online: 15 July 2019

(C) Springer Nature Switzerland AG 2019

The articles in this issue of Postdigital Science and Education display what appears to be a conspicuous lack of specific engagement with digital technology. Across the span of contributions, we find Chris Jones (2019) considering capital and neoliberalism; Tim Fawns, Gill Aitken and Derek Jones (2019) discussing embodied, socially meaningful experiences; Carlos Escaño (2019) unpicking the biopolitical commons; Peter McLaren (2019) meandering through evangelicalism, socialism, and US foreign policy, and Steve Fuller (2019) interrogating the knowledge economy, to name but a few. Of course, it is also entirely appropriate to suggest that the articles in this issue examine the digital with a rigour, care, and authenticity that ought to be more prevalent in discussions of technology. How can both these appearances ring true? The rather unsatisfactory but concise answer is that digital technology is no longer just digital technology (and of course, it never was). A much better answer needs some elaboration (and is developed in this issue by the collective writing groups led by Sonja Arndt and Dave Cormier) (Arndt et al. 2019; Cormier et al. 2019). While the topics covered in this issue may seem somewhat indiscriminate, they are of course rather significant ways of understanding the digital. Conversely, the digital is also a rather significant way of understanding politics, society, and economics in our current era. In other words, as the various articles demonstrate, the digital is so intimately entwined in our lived experiences and institutions that to set boundaries around some gadget or device seems somewhat arbitrary. Indeed, the rich potential of the postdigital is precisely to open up new ways of thinking about the digital and to frame such discussions not only in the context of longstanding philosophical and theoretical questions but also in relation to contemporary concerns. In this issue, we find examples of the former in Glenn Rikowski and Derek Ford's (2019) dialogue on schools, education and time, and examples of the latter in Ronald Barnett's (2019) commentary on universities, populism, and social division.

Across the issue, we find an interest in the politics of the digital and a recognition of its much more productive relations with the economy. Indeed, to follow Richard Hall's contribution to the collective piece 'Ten Years of the Postdigital in the 52group:

Jeremy Knox

jeremy.knox@ed.ac.uk

1 Centre for Research in Digital Education, The University of Edinburgh, Edinburgh, UK 
Reflections and Developments 2009-2019' (Cormier et al. 2019), it is precisely the separation of politics and economics that is at stake, such that the digital appears to offer increasingly less for notions of public life (doesn't it seem such a very long time ago that we all learned how social media platforms were actually about advertising revenue, rather than keeping up with friends or mobilising grassroots activism?). Indeed, one of the recurring threads in these reflections on the postdigital appears to be the shifting perceptions of online spaces, from early emancipatory potentials to later disillusionment and increasing corporatisation. So, what happened to the politics of the digital? Or perhaps we might better ask as we publish this second issue of the journal: what kind of politics might we enact through the postdigital?

Certainly, part of the critical thrust of the postdigital is to attempt to decentre the technology of the digital itself, so that its relations to broader frameworks are brought to the fore. One important area of research that is foregrounding the political in this way is the critical study of data-driven technologies, such as artificial intelligence, machine learning, and algorithmic systems. A key example in this area is Crawford and Joler's 'Anatomy of an AI System', which, through a large visualisation and accompanying text, defines a particular brand of 'smart speaker' in terms of broad relations between 'human labor, data and planetary resources' (2018). In other words, we are encouraged to understand the 'AI' here, not simply as 'a small cylinder in your living room' (Crawford and Joler 2018), but as a vast network of exploitative working conditions, for example in mining, manufacture, and data-labelling, as well as an immense system of contingent decision-making across Internet infrastructures and machine learning systems. This not only decentres the technology but allows us to see how it is situated within much more expansive and longstanding political issues. Part of this interest in exposing the geopolitics of digital technologies derives from a concern that the technology industry itself appears to habitually frame ethical issues as a matter of their own engineering. The most recent report from the AI Now institute at New York University cautions against the tendency to 'reframe political questions as technical concerns' (Whittaker et al. 2018:32). Further, they suggest:

historical patterns of discrimination and classification, which often construct harmful representations of people based on perceived differences, are reflected in the assumptions and data that inform AI systems, often resulting in allocative harms. This perspective requires one to move beyond locating biases in an algorithm or dataset, and to consider 'the role of AI in harmful representations of human identity,' and the way in which such harmful representations are both shaped, and shape, our social and cultural understandings of ourselves and each other. (Whittaker et al. 2018: 25)

The key point here is that such technologies need to be seen as, not only 'fitting in' to more established political contexts but also working to amplify and intensify those contexts in unprecedentedly precise and transmissive ways.

This is precisely the 'wide angle lens' that the postdigital offers and that is surfaced throughout this issue; to acknowledge the broader environments through which powerful digital systems are located and operate. Returning the digital to the political in this way may be a crucial aspect of postdigital work to come. It is notable that even the data 
scientist - that most apolitical of professions, combining the supposed neutrality of computing and the assumed detachment of science - has recently been placed in the frame for politicisation. In calling for a wide-ranging 'politics of justice' for those working with data-driven technologies, Green suggests: 'Data scientists must recognize themselves as political actors engaged in normative constructions of society and, as befits political work, evaluate their work according to its downstream material impacts on people's lives'. (Green 2019: 7).

This is part of the shift towards political work that I sense in this issue of Postdigital Science and Education, and a signal, perhaps, of the continued critical work needed in this area.

\section{References}

Arndt, S., Asher, G., Knox, J., Ford, D. R., Hayes, S., Lăzăroiu, G., Jackson, L., Mañero Contreras, J., Buchanan, R., D’Olimpio, L., Smith, M., Suoranta, J., Pyyhtinen, O., Ryberg, T., Davidsen, J., Steketee, A., Mihăilă, R., Stewart, G., Dawson, M., Sinclair, C., \& Peters, M. A. (2019). Between the blabbering noise of individuals or the silent dialogue of many: a collective response to 'Postdigital Science and Education' (Jandrić et al. 2018). Postdigital Science and Education. https://doi.org/10.1007/s42438-019$00037-y$.

Barnett, R. (2019). University Challenge: Division, Discourse and Democracy. Postdigital Science and Education. https://doi.org/10.1007/s42438-019-00044-z.

Cormier, D., Jandrić, P., Childs, M., Hall, R., White, D., Phipps, L., Truelove, I., Hayes, S., \& Fawns, T. (2019). Ten years of the postdigital in the 52group: reflections and developments 2009-2019. Postdigital Science and Education. https://doi.org/10.1007/s42438-019-00049-8.

Crawford, K., \& Joler, V. (2018). The Anatomy of an AI System. https://anatomyof.ai/. Accessed 25 June 2019.

Escaño, C. (2019). Biopolitical commons in the postdigital era. Postdigital Science and Education. https://doi. org/10.1007/s42438-019-00041-2.

Fawns, T., Aitken, G., \& Jones, D. (2019). Online learning as embodied, socially meaningful experience. Postdigital Science and Education. https://doi.org/10.1007/s42438-019-00048-9.

Fuller, S. (2019). Against academic rentiership: a radical critique of the knowledge economy. Postdigital Science and Education. https://doi.org/10.1007/s42438-019-00035-0.

Green, B. (2019). Data science as political action: grounding data science in a politics of justice. arXiv:1811.03435. Accessed 25 June 2019.

Jones, C. (2019). Capital, neoliberalism and educational technology. Postdigital Science and Education. https://doi.org/10.1007/s42438-019-00042-1.

McLaren, P. (2019). God and governance: reflections on living in the belly of the beast. Postdigital Science and Education. https://doi.org/10.1007/s42438-019-00050-1.

Rikowski, G., \& Ford, D. R. (2019). Marxist education across the generations: a dialogue on education, time, and transhumanism. Postdigital Science and Education. https://doi.org/10.1007/s42438-018-0028-1.

Whittaker, M., Crawford, K., Dobbe, R., Fried, G., Kaziunas, E., Mathur, V., West, S.M., Richardson, R., Schultz, J., \& Schwartz, O. (2018). AI Now Report. https://ainowinstitute.org/AI_Now_2018_Report.pdf. Accessed 25 June 2019. 